\title{
ORIGINAL
}

\section{Change in perception of the quality of death in the intensive care unit by healthcare workers associated with the implementation of the "well-dying law"}

Ye Jin Lee', Soyeon Ahn², Jun Yeun Cho ${ }^{3}$, Tae Yun Park ${ }^{4}$, Seo Young Yun ${ }^{4}$, Junghyun Kim ${ }^{5}$, Jee-Min Kim ${ }^{5}$, Jinwoo Lee ${ }^{1}$, Sang-Min Lee ${ }^{1}$, Jong Sun Park ${ }^{6}$, Young-Jae Cho ${ }^{6}$, Ho II Yoon ${ }^{6}$, Jae Ho Lee ${ }^{6}$, Choon-Taek Lee ${ }^{6}$ and Yeon Joo Lee 6* $^{*}$

\begin{abstract}
Purpose: The importance of dying with dignity in the intensive care unit (ICU) has been emphasized. The South Korean government implemented the "well-dying law" in 2018, which enables patients to refuse futile life-sustaining treatment (LST) after being determined as terminally ill. We aimed to study whether the well-dying law is associated with a significant change in the quality of death in the ICU.
\end{abstract}

Methods: The Quality of Dying and Death (QODD) questionnaires were prospectively collected from the doctors and nurses of deceased patients of four South Korean medical ICUs after the law was passed (January 2019 to May 2020). Results were compared with those of our previous study, which used the same metric before the law was passed (June 2016 to May 2017). We compared baseline characteristics of the deceased patients, enrolled staff, QODD scores, and staff opinions about withdrawing LST from before to after the law was passed.

Results: After the well-dying law was passed, deceased patients $(N=252)$ were slightly older $(68.6$ vs. $66.6, p=0.03)$ and fewer patients were admitted to the ICU for post-resuscitation care (10.3\% vs. 20\%, $p=0.003)$. The mean total QODD score significantly increased after the law was passed (36.9 vs. 31.3, $p=0.001)$. The law had a positive independent association with the increased QODD score in a multiple regression analysis.

Conclusion: Our study is the first to show that implementing the well-dying law is associated with quality of death in the ICU, although the quality of death in South Korea remains relatively low and should be further improved.

Keywords: Quality of death and dying, Intensive care unit, Well-dying law

\footnotetext{
*Correspondence: yjlee1117@snubh.org

${ }^{6}$ Division of Pulmonary and Critical Care Medicine, Department

of Internal Medicine, Seoul National University Bundang Hospital, 82

Gumi-ro 173 beon-gil Bundang-gu, Seongnam-si, Gyeonggi-do, Republic

of Korea
}

Full author information is available at the end of the article

\section{鱼




\section{Introduction}

The importance of dying with dignity in intensive care units (ICUs) is emphasized, and early discussion with patients and families about the goals of care is a key factor for improving the quality of end-of-life care [1-3]. However, due to the Confucian social order and "Boramae Hospital incident" in 1997 [4], discussion on dying with dignity was not actively conducted in South Korea. In the Boramae Hospital incident, the Supreme Court of Korea convicted doctors for aiding and abetting a homicide because the doctors ordered the discharge of a patient in a vegetative state after brain surgery in deference to the insistent requests of the patient's wife. After this case judgment, South Korean physicians were extremely cautious about requests of the patient's family to discontinue life-sustaining treatment (LST), and discussion on death with dignity was shirked for subsequent years.

Social demand for "dying with dignity" was intensified due to the "Grandma Kim" incident in 2009. Grandma Kim was in a persistent vegetative state from brain damage due to a massive hemorrhage during a lung biopsy, and her family wanted to stop ventilatorassisted breathing. In 2009, the Supreme Court allowed ventilatory support withdrawal after much social discussion and debate, setting a precedent in South Korea by acknowledging the right to die with dignity. Since then, social interest in dying with dignity continued. The South Korean government finally enacted the Hospice, Palliative Care and Life-sustaining Treatment Decision-making Act, also known as the "well-dying law," in February 2016 and fully implemented this Act in February 2018 [5]. This law enables patients to refuse cardiopulmonary resuscitation (CPR), ventilator support, hemodialysis, or anticancer treatment following a diagnosis of being near death from terminal illness by their primary and secondary specialist doctors. This law presupposes that the patient's self-determination should be prioritized. If the patient's will cannot be estimated, LST can be discontinued based on the agreement of the whole family and confirmation of two doctors or a decision by a legitimate family substitute and two doctors.

Therefore, implementing the well-dying law is expected to reduce non-beneficial LST for incapacitated patients with advanced illnesses. This study aimed to compare the quality of death in the ICU before and after implementing the law using the Quality of Dying and Death (QODD) questionnaire among ICU staff responsible for deceased patients and investigate the factors associated with better quality of death in the ICU.

\section{Take-home message}

Our prospective multicenter survey demonstrated that the legislation regarding end-of-life decision, called "well-dying law", was associated with significant improvement in the quality of dying compared with what noted before the law. In addition, we showed that the ethical and legal issues associated with life-sustaining treatment withdrawal have improved after the introduction of the law, but the quality of death in South Korean intensive care units appears relatively low, with much scope for improvement in the quality of care, especially with regard to patient autonomy near death.

\section{Methods}

\section{Study design and participants}

This prospective study was based on a previous study [6] conducted from June 2016 to May 2017, before the implementation of the well-dying law, to evaluate the quality of dying in South Korean ICUs. To compare the quality of death after the implementation of the law, we conducted a survey using the same questionnaire in the same ICUs as that in the previous study [6]. The same methods were used in both time periods. From January 2019 to May 2020 (following the implementation of the well-dying law), we enrolled the medical staff responsible for caring for dying patients in four medical ICUs of Seoul National University Bundang Hospital, Seoul National University Hospital, Seoul Boramae Hospital, and National Medical Center. The four ICUs had the same policy of ICU visits; family visits were possible only twice a day, once in the morning and afternoon.

Medical staff of the deceased patients were requested to complete the Korean version of the QODD [7] within $48 \mathrm{~h}$ of the patient's death. In addition, after completing the QODD questionnaire, we asked questions about the staff's opinion of the best action and actual action on the withdrawal of LST in the deceased patient (the questions are described in Supplemental Table S1).

Information about the deceased patients' demographics, reason for ICU admission, length of stay, use of lifesupport equipment, CPR within $24 \mathrm{~h}$ of death, stipulation of a do not resuscitate (DNR) order, and medications within $24 \mathrm{~h}$ of death was obtained from medical charts.

This study was approved by the institutional review board of each participating hospital (IRB number: B-1903-531-302). Written informed consent was obtained from the study participants, and the consent of the deceased patient was waived.

\section{QODD}

We used the Korean version of the QODD (version 3.2) [7, 8], which comprises of 20 items in three domains: patient's experience at the end of life (15 questions); medical care at the end of life (3 questions); and experience at the point of death ( 2 questions). Items were rated 
from 0 (terrible experience) to 10 (excellent experience). The total QODD score was calculated on a 0 to 100 scale, with a higher score indicating a higher quality of dying.

\section{Statistical analyses}

To compare the quality of dying before and after the implementation of the well-dying law, we used previously published data from our group that represented the quality of dying before the implementation of the law [6]. We performed the Student's $t$-test or Mann-Whitney $U$ test to compare the mean score of each questionnaire item assessed in our previous and present QODD studies by the medical staff. The Fisher's exact test or Pearson chisquare test was performed for categorical variables, and the Pearson correlation coefficient was calculated for continuous variables. A multiple linear regression analysis was performed for studying the correlation between increase in the QODD score and variables. We assumed that there would be a change in the use of sedatives, analgesics, and inotropes after the well-dying law. Therefore, a-priori pairwise correlation analysis was conducted to exclude the factors that might be due to the implementation of the law. These three factors had significant negative correlation with the law. In addition, we performed interrupted time series (ITS) analyses to capture the time trend [9]. The following equation was finally adopted.

$$
\begin{aligned}
\text { QODDt }= & \beta 0+\beta 1 \times \text { time }_{t}+\beta 2 \times \text { Implementation of the law } \\
& +\beta 3 \times \text { factor } 1+\beta 4 \times \text { factor } 2+\cdots+\varepsilon t .
\end{aligned}
$$

where QODDt was a person-level QODD value at time $t$, $\beta 1$ was the time trend in QODD value, $\beta 2$ was the immediate level change of QODD after the law implementation, and $\beta 3$ was the coefficient of a possible confounder, and $\varepsilon t$ was an error term. A linear mixed effect model with the hospital and medical staff as random effects was further performed using the same model specification in the ITS. STATA 13 (STATA Corp LP., College Station, TX, USA) and R version 4.0.3 were used for the statistical analyses.

\section{Results}

\section{Baseline characteristics}

Similar to the previous study (416 questionnaires completed by 177 ICU staff ( 66 doctors and 111 nurses) of 255 deceased patients), in this study period, 414 questionnaires by 143 staff ( 50 doctors and 93 nurses) corresponding to 252 deceased patients were collected. The distribution of survey received from medical staff across the study period as a timeline is shown in Supplemental Fig. S1.

A comparison of the baseline characteristics of the deceased patients for the two periods are shown in Table 1. During the period after the law was passed, the deceased patients were slightly older (68.6 vs. 66.6, $p=0.03$ ) and fewer patients were admitted to ICU for post-resuscitation care $(10.3 \%$ vs. $20 \%, p=0.003)$.

Patients treated after the implementation of the law were less likely to receive sedatives, inotropes, and analgesics within $24 \mathrm{~h}$ of death than those treated before the implementation of the law. The time from DNR to death was longer in patients after the law was implemented ( 2.6 vs. $5.3, p=0.020$ ). The participating medical staff characteristics are described in Supplemental Table S2. Staff enrolled after the law was passed were significantly younger and had less experience than those enrolled before the law. The number of staff trained on comfort care for more than $6 \mathrm{~h}$ (14.7\%) tended to be slightly higher than that in the period before the law $(10.2 \%$; $p=0.06$ ).

\section{QODD items and score}

Figure 1 and Supplemental Table S3 present a comparison of total QODD scores and individual ratings for each questionnaire item before and after the law was implemented. The mean total QODD score after the welldying law was passed was significantly higher than that before the law was passed ( 36.9 vs. $31.3, p=0.001)$. Similar results were observed in the doctor and nurse subgroups (mean difference in doctors, 5.6, $p=0.001$; and in nurses, 5.5, $p=0.004$, Table S3). Two items, Q18 and Q19 showed the highest increase (0.9-point) in the score after the law. The scores of 15 items significantly improved after implementation of the law, and five items did not significantly improve: Q1, Q2, Q3, Q7, and Q20.

\section{Factors affecting the QODD}

Factors associated with better quality of death are shown in Table 2. Multiple regression analysis showed that the law had a positive independent association with the increased QODD score (5-point increase). CPR performed within $24 \mathrm{~h}$ of death had a negative independent association with the quality of death. The presence of cancer and higher age was associated with better quality of death. The use of sedatives, analgesics, and inotropes within $24 \mathrm{~h}$ of death were significantly correlated with the implementation of the well-dying law and were excluded from multiple regression analysis (Table 2). In the ITS analysis, we found similar results that the well-dying law implementation was associated with increased QODD scores (coefficient: 7.23, $p=0.039$ ) whereas the time that elapsed during the pre-period or post-period was not associated with increased QODD score (coefficient: 0.00, $p=0.533$ ) (Supplemental Table S4 and Fig. 2). The linear mixed model also showed that the law implementation had a significantly positive association with QODD 
Table 1 Baseline characteristics of patients who died in ICUs before and after the implementation of the well-dying law

\begin{tabular}{|c|c|c|c|}
\hline Characteristics & $\begin{array}{l}\text { Before well-dying law } \\
(N=255)\end{array}$ & $\begin{array}{l}\text { After well-dying law } \\
(N=252)\end{array}$ & $p$-value \\
\hline Sex (male) & $159(62.4)$ & $173(68.7)$ & 0.250 \\
\hline Age, years & $66.6 \pm 14.1$ & $68.6 \pm 13.1$ & 0.030 \\
\hline \multicolumn{4}{|l|}{ Reason for ICU admission } \\
\hline Respiratory failure & $149(58)$ & $130(51.6)$ & 0.160 \\
\hline Sepsis & $59(23.1)$ & $54(21.4)$ & 0.750 \\
\hline Post-resuscitation care & $51(20)$ & $26(10.3)$ & 0.003 \\
\hline Renal failure & $35(13.7)$ & $42(16.7)$ & 0.390 \\
\hline Heart failure & $22(8.6)$ & $36(14.3)$ & 0.050 \\
\hline Hemorrhagic shock & $7(2.7)$ & $16(6.4)$ & 0.060 \\
\hline APACHE ॥ & $29.5 \pm 15$ & $25.7 \pm 9.7$ & 0.001 \\
\hline SOFA & $11.8 \pm 6.4$ & $9 \pm 5.3$ & $<0.001$ \\
\hline Hospital day & $20.6 \pm 27.4$ & $21.1 \pm 24.7$ & 0.840 \\
\hline Length of ICU stay & $6.6 \pm 6.9$ & $7.6 \pm 7.3$ & 0.125 \\
\hline Malignancy & $101(39.6)$ & $94(37.3)$ & 0.710 \\
\hline Life-support equipment & $245(95.3)$ & $234(92.9)$ & 0.263 \\
\hline MV & $228(89.4)$ & $221(87.7)$ & 0.580 \\
\hline RRT & $124(48.6)$ & $119(47.2)$ & 0.720 \\
\hline ECMO & $17(6.7)$ & $10(4)$ & 0.240 \\
\hline IABP/pacemaker & $9(3.5)$ & $0(0)$ & 0.004 \\
\hline \multicolumn{4}{|c|}{ Medications within $24 \mathrm{~h}$ before death } \\
\hline Sedative & $128(48.9)$ & $96(38.1)$ & 0.020 \\
\hline Analgesics & $158(60.3)$ & $85(33.7)$ & $<0.001$ \\
\hline Inotropes & $239(91.2)$ & $124(49.2)$ & $<0.001$ \\
\hline CPR within $24 \mathrm{~h}$ before death & $48(18.8)$ & $57(22.9)$ & 0.270 \\
\hline GCS within $24 \mathrm{~h}$ before death & $3.8 \pm 1.9$ & $3.3 \pm 1.4$ & $<0.001$ \\
\hline DNR documentation & $206(80.8)$ & $206(81.8)$ & 0.820 \\
\hline Time to death from DNR & $2.6 \pm 7.8$ & $5.3 \pm 15.2$ & 0.020 \\
\hline
\end{tabular}

ICU intensive care unit; APACHE II acute physiology and chronic health evaluation II; SOFA Sequential Organ Failure Score; MV mechanical ventilation; RRT renal replacement therapy; ECMO extracorporeal membrane oxygenation; IABP intra-arterial balloon pump; CPR cardiopulmonary resuscitation; GCS Glasgow Coma Scale; DNR do not resuscitate

(coefficient: $8.49, p=0.019$ ), while CPR performed within $24 \mathrm{~h}$ of death (coefficient: $-6.17, p \leq 0.001$ ) and having two or more life supporting equipment (coefficient: $-2.77, p=0.023$ ) were negatively associated with the QODD score (Supplemental Table S5).

\section{Participating medical staff's opinion of the best action and actual action for LST withdrawal}

The participating medical staff were additionally asked the following questions (Supplemental Table S1) at the end of the QODD questionnaire. The concordance rate of the staff's opinion of the best action and the actual action for LST withdrawal significantly increased after the law compared to that before the law $(40.8 \%$ vs. $60.8 \%$, respectively, $p<0.001$ ). The reasons for discordance between the opinion and action are described in Table 3. The reasons given by the medical staff for the discrepancies between the best action and actual action were "ethical problems" (18.8\%) and "not guaranteed by law" (30.6\%)", although they recognized that the patients received non-beneficial LST before the implementation of the well-dying law. However, those reasons were significantly reduced to $2.5 \%$ and $21.9 \%$ after the well-dying law implementation, respectively (Table 3 ).

\section{Discussion}

This study is the first to identify the effect of the welldying law on the quality of death in ICUs. As expected, there was a significant improvement in the quality of dying (QODD score) after the well-dying law implementation. The well-dying law had a positive independent association with the increased QODD score in the multiple regression analysis, ITS analysis, and multilevel adjustment analysis. In addition, the concordance rate of the medical staff's opinion of the best action and actual 


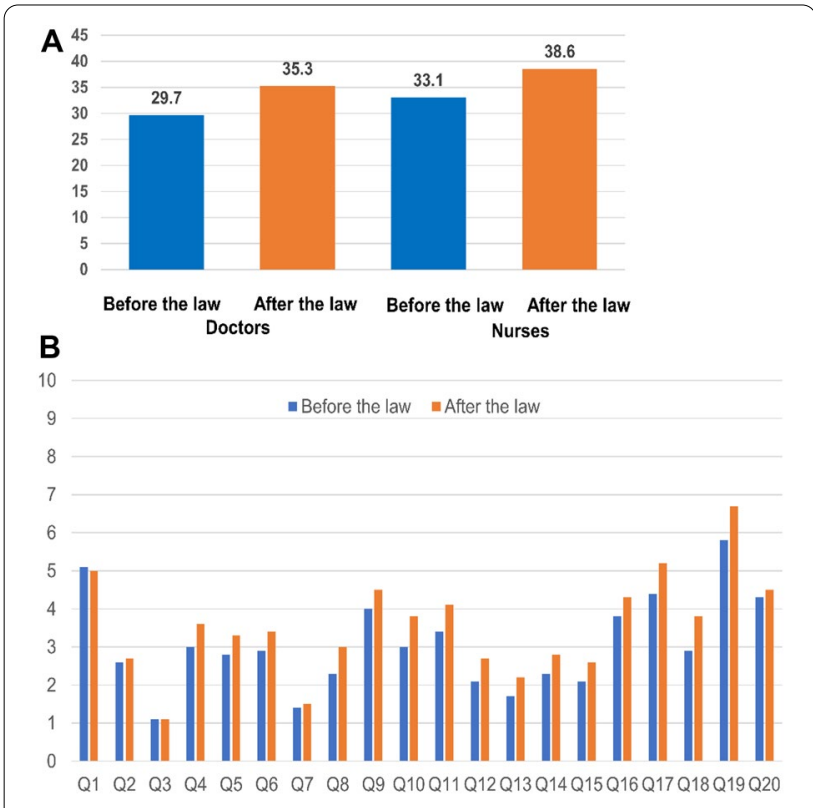

Fig. 1 Comparison of the quality of dying and death scores before and after the well-dying law. A Total QODD scores in the doctor and nurse groups before and after the well-dying law. B Individual QODD scores for each questionnaire item before and after the well-dying law. For each questionnaire, the medical staff was asked to rate the quality of each experience on a $0-10$ scale, with a score of 0 indicating terrible experience and 10 indicating excellent experience. Q1: Having pain under control; Q2: Having control over what is going on around you; Q3: Being able to feed oneself; Q4: Being able to breathe comfortably; Q5: Feeling at peace with dying; Q6: Feeling unafraid of dying; Q7: Being able to laugh and smile; Q8: Keeping one's dignity and self-respect; Q9: Spending time with family and friends; Q10: Spending time alone; Q11: Being touched or hugged by loved ones; Q12: Saying goodbye to loved ones; Q13: Clearing up bad feelings; Q14: Visits from religious advisor; Q15: Spiritual service before death; Q16: Experience of receiving mechanical ventilation; Q17: Experience of receiving dialysis; Q18: Discussion with doctors about wishes; Q19: Anyone present at moment of death; Q20: State at moment of death; QODD: Quality of Death and Dying

action for the LST withdrawal was significantly increased after the implementation of the law.

As mentioned in the results section, the time between receiving a DNR and death increased from 2.5 to 5 days following the implementation of the law. This implies that the "well-dying" law provides an extended opportunity to communicate about death and withdrawal of LST between medical staff and the caregiver/patient much earlier than the point of death. Moreover, the concordance rate of the staff's opinion of the best action and actual action for LST withdrawal showed a $20 \%$ increase after the implementation of the law. These findings reflect that the ethical and legal issues around LST withdrawal have been improved by the well-dying law, enabling physicians to act according to their clinical judgment to limit futile LST, thereby leading to an increased concordance between the opinion and the action of LST withdrawal.

The scores of all individual questionnaire items increased after the law. However, both doctors and nurses gave less than three-point scores for the following seven items on the QODD regardless of the enactment of the law: "Q2, 3, 7, 12, 13, 14, and 15" questions about patient autonomy and emotional support at the point of death. The patient's autonomy on end-of-life care is exercised through communication, which may be impossible if the patient lacks the capability. The communication for incapable patients is conveyed through an advanced directive [10] written by patients when they were mentally and physically healthy and could sufficiently consider and decide the right choice of treatment or surrogate decision-making by family, representing autonomy. Therefore, if there is sufficient information for the patient and family, for example, on when to write, what to decide, and others, (i.e., if this information are provided), the patient's autonomy over the end of life could be enhanced. The implementation of extended visitation or an unrestricted visiting policy can alleviate the psychological distress of patients and improve the quality of death $[11,12]$. Visiting the ICU is strictly limited to once or twice a day due to concern about distractions from visitors $[13,14]$ in many countries. Only when the patient is on the verge of death can the caregiver visit the patient more than twice a day in most South Korean ICUs. However, Netzer et al. demonstrated that the extended family visiting hours in the ICU reduced the patient's delirium and improved family satisfaction without affecting the infection rate [15].

A major obstacle that needs to be overcome to improve the quality of death is the disagreement among family members. The problem emerges from the phrase "agreement of the whole family" in the law. If a member of the family is unreachable or missing, this violates the essentials of the legal agreement of the whole family. In fact, the number of cases where LST withdrawal could not be performed due to disagreement among families of patients for whom withdrawal was considered increased by more than $20 \%$, from $33.3 \%$ to $58.8 \%$, after the enactment of the law (Table 3). Thus, the medical community has emphasized the need to modify the well-dying law to narrow the scope of family members (from "whole family" to "two family members"). As a result, on December 11, 2018, the Well-Dying Act was amended in this regard, and the revised version became effective on March 28, 2019 [16]. This study was conducted between January 2019 and May 2020; therefore, most of the data extracted for this study should have reflected the implementation of this law, this was not the case. This is because information on the revised law 
Table 2 Factors associated with better quality of death in ICUs

\begin{tabular}{|c|c|c|c|c|c|c|}
\hline Factors & Total QODD score & $p$-value & Doctors & $p$-value & Nurses & $p$-value \\
\hline Implementation of the well-dying law & & $<0.001$ & & $<0.001$ & & 0.004 \\
\hline Before & $31.3 \pm 17$ & & $29.7 \pm 15.3$ & & $33.1 \pm 18.4$ & \\
\hline After & $36.9 \pm 19.8$ & & $35.3 \pm 19.3$ & & $38.6 \pm 20.3$ & \\
\hline Underlying cancer & & 0.037 & & 0.529 & & 0.020 \\
\hline Malignancy & $35.9 \pm 18.7$ & & $33.1 \pm 16.7$ & & $38.8 \pm 20.2$ & \\
\hline No malignancy & $33 \pm 18.5$ & & $31.9 \pm 18.3$ & & $34.3 \pm 18.7$ & \\
\hline CPR within $24 \mathrm{~h}$ of death & & $<0.001$ & & $<0.001$ & & 0.016 \\
\hline Performed & $28.2 \pm 18.7$ & & $25.9 \pm 16.5$ & & $30.7 \pm 20.7$ & \\
\hline Not performed & $35.8 \pm 18.2$ & & $34.4 \pm 17.5$ & & $37.3 \pm 18.8$ & \\
\hline Life-supporting equipment & & 0.128 & & 0.177 & & 0.389 \\
\hline$\geq 2$ & $32.4 \pm 17.3$ & & $30.4 \pm 15.6$ & & $34.5 \pm 18.8$ & \\
\hline$<2$ & $35.5 \pm 19.4$ & & $34.1 \pm 19$ & & $36.9 \pm 19.8$ & \\
\hline Continuous variables & $R$ & $p$-value & $R$ & $p$-value & $R$ & $p$-value \\
\hline Age, years & 0.1 & 0.033 & 0.082 & 0.2 & 0.126 & 0.069 \\
\hline APACHE-II & -0.067 & 0.213 & -0.064 & 0.364 & -0.063 & 0.439 \\
\hline ICU length of stay & 0.064 & 0.137 & 0.116 & 0.044 & 0.014 & 0.828 \\
\hline
\end{tabular}

QODD quality of death and dying; CPR cardiopulmonary resuscitation; APACHE II acute physiology and chronic health evaluation II; ICU intensive care unit

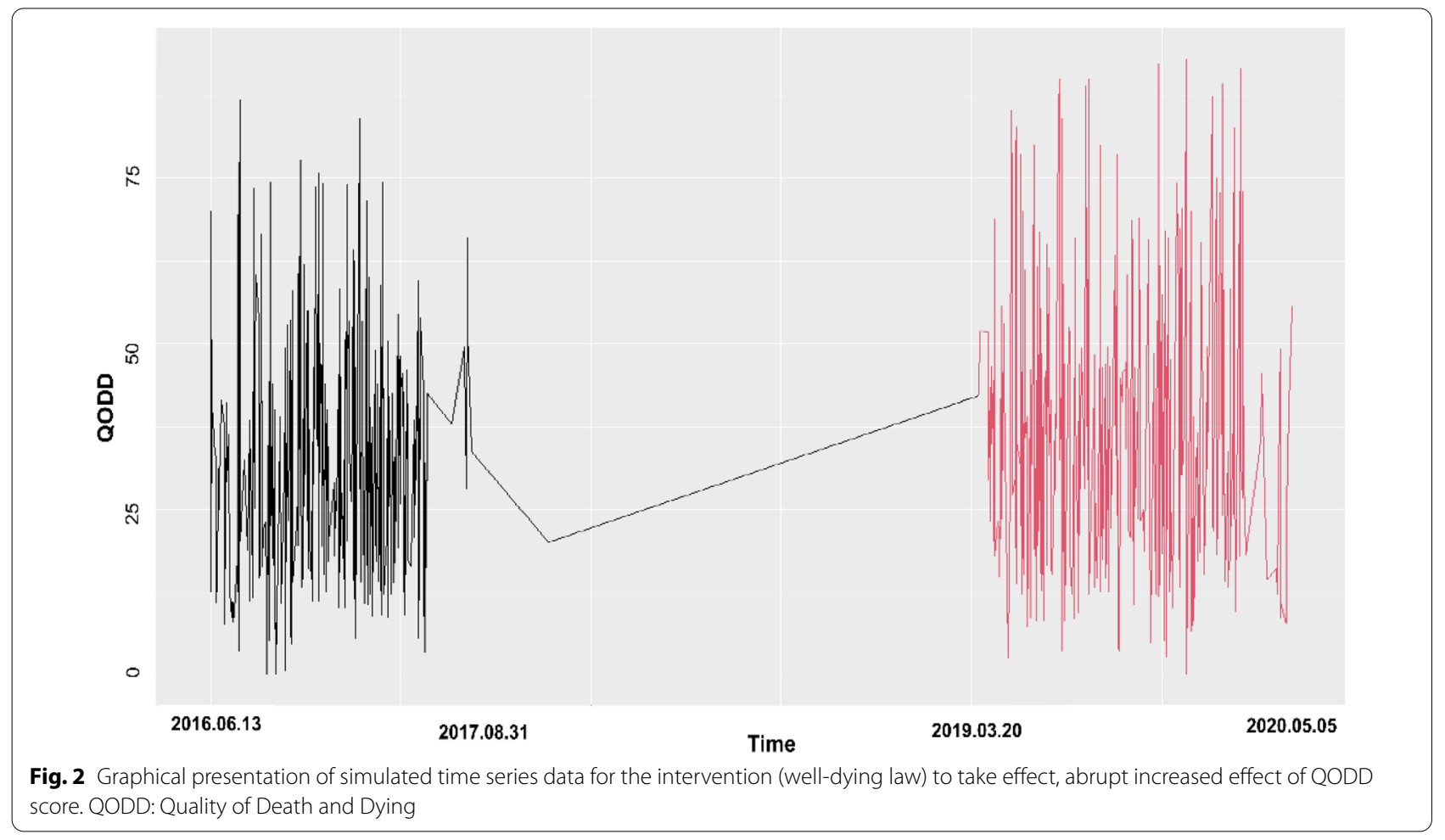

content was not widely disseminated in the clinical field during the study period.

Despite the increase after the law was implemented, the QODD score in South Korea is far below that of Western countries, considering the QODD score of 60-70 in the
United States or the Netherlands (supplementary Fig. S2) [17-21]. This may due to the cultural differences in endof-life communication. In the Korean Confucian culture, direct discussion about dying is disrespectful, and communication on the issue has long been discouraged. Ko 
Table 3 Comparison of the medical staff's opinion of the best action and actual action for withdrawal of life-sustaining treatment before and after the well-dying law

\begin{tabular}{|c|c|c|c|}
\hline Questions about withdrawal of life-sustaining treatment & $\begin{array}{l}\text { Before the well-dying } \\
\text { law }(N=353)\end{array}$ & $\begin{array}{l}\text { After the well-dying } \\
\text { law }(N=403)\end{array}$ & $p$-value \\
\hline $\begin{array}{l}\text { (a) Have you ever thought that the deceased patient needed withdrawal of } \\
\text { LST? } \\
\text { (b) If yes, did you actually withdraw any of the LST? }\end{array}$ & $n(\%)$ & $n(\%)$ & \\
\hline (a) Yes $\rightarrow$ (b) Yes & $144(40.8)$ & $245(60.8)$ & $<0.001$ \\
\hline (a) $\mathrm{Yes} \rightarrow$ (b) No & $142(40.2)$ & $119(29.5)$ & 0.09 \\
\hline $\begin{array}{l}\text { (c) Although you thought that the patient needed withdrawal of LST, you did } \\
\text { not withdraw the LST. What was the main reason? }\end{array}$ & & & $<0.001$ \\
\hline Disagreement among family members & $48(33.3)$ & $70(58.8)$ & \\
\hline Case not guaranteed by the law at the time of study questionnaire & $42(30.6)$ & $26(21.9)$ & \\
\hline Ethical problem & $27(18.8)$ & $3(2.5)$ & \\
\hline Other & $25(17.4)$ & $20(16.8)$ & \\
\hline
\end{tabular}

The medical staff who participated in this study were asked the above-mentioned questions at the end of the questionnaire

LST life-sustaining treatment

and Lee found that non-Hispanic white patients were more likely to receive discussions about end-of-life care than South Korean Americans [22]. South Koreans tend to avoid conveying any negative information about poor prognosis to their parents and defer open discussion until it is inevitably discussed in proximity to death in many cases [23]. However, the results of our study are not representative of all Confucian countries. There are significant intra-region differences in the ICU physicians' practices of LST, the roles of families, their understanding of legal risks, and financial considerations in the same Confucian Asian countries [24, 25].

This study has some limitations. First, the QODD was only assessed by nurses and physicians and did not include the family perspective. Second, the before-after design limits the ability to make causal inference as other temporal changes may have confounded the results. However, we performed an ITS analysis, which suggested that the effect of the temporal changes was minimal. Third, the participants were possibly biased, as they were from medical ICUs. Therefore, our results may not be generalizable to other specialized ICUs (e.g., surgical or neurological). However, considering the severity of patients' conditions and number of deaths in the medical ICU compared with those in other ICUs, the frequency of discussion about end-of-life care, LST, and withdrawal must be most frequent in the medical ICU, making the staff suitable for this study. Fourth, the same medical staff answered the QODD questions multiple times due to the limited staff at each hospital. Therefore, multiple comparisons may have resulted in some spurious associations. However, we tried to minimize duplicated participation by limiting response frequencies to five per physician and three per nurse in a month. In addition, multilevel approach using a linear mixed model showed same result. Fifth, we could not assess if the actual use of ICU resources decreased in non-beneficial LST for incapacitated patients with advanced illnesses. Our study was conducted to analyze the quality of dying in the ICU, therefore, we enrolled patients who were already admitted to the ICU and died in the ICU. Patients who had decided not to receive meaningless LST would not have been admitted to the ICU at all. Further studies including the overall in-hospital mortality are needed to analyze whether the use of meaningless LST has decreased.

\section{Conclusion}

In conclusion, our findings suggest that the implementation of the well-dying law positively affected the quality of death in the ICU and improved the ethical and legal issues associated with LST withdrawal, thereby enabling physicians to act according to their clinical judgment and limited futile LST. Nonetheless, the quality of death in South Korean ICUs appears relatively low, with much scope for improvement in the quality of care, especially with regard to patient autonomy near death. The welldying law in South Korea should be revised to improve effectiveness in accordance with clinical opinions.

\section{Supplementary Information}

The online version contains supplementary material available at https://doi. org/10.1007/s00134-021-06597-7.

\footnotetext{
Author details

${ }^{1}$ Division of Pulmonary and Critical Care Medicine, Department of Internal Medicine, Seoul National University Hospital, Seoul, Republic of Korea. ${ }^{2}$ Division of Statistics, Medical Research Collaborating Center, Seoul National University Bundang Hospital, Seongnam, Republic of Korea. ${ }^{3}$ Division of Pulmonary and Critical Care Medicine, Department of Internal Medicine, Chungbuk National University Hospital, Chungbuk National University College of Medicine, Cheongju-si, Republic of Korea. ${ }^{4}$ Division of Pulmonary and Critical Care Medicine, Department of Internal Medicine, Seoul Metropolitan
} 
Government-Seoul National University Boramae Medical Center, Seoul, Republic of Korea. ${ }^{5}$ Division of Pulmonary and Critical Care Medicine, Department of Internal Medicine, National Medical Center, Seoul, Republic of Korea. ${ }^{6}$ Division of Pulmonary and Critical Care Medicine, Department of Internal Medicine, Seoul National University Bundang Hospital, 82 Gumi-ro 173 beon-gil Bundang-gu, Seongnam-si, Gyeonggi-do, Republic of Korea.

\section{Acknowledgements}

The authors thank Division of Statistics in Medical Research Collaborating Center at Seoul National University Bundang Hospital for statistical analysis.

\section{Author contributions}

Concept and design: YJL, JYC, TYP, SYY, JK, JMK, JL, SML, and YJL (the corresponding author) Data collection, analysis, or interpretation of data: YJL, SA, JYC, TYP, SYY, JK, JMK, JL, SML, and YJL (the corresponding author). Drafting the manuscript:YJL, SA and YJL (corresponding author). Critical revision of the manuscript for important intellectual content and approved the version to be published: all authors. Obtained funding: YJL (the corresponding author).

\section{Funding}

The corresponding author (YJL) was supported by the SNUBH Research Fund (Grant Number 06-2019-098). Role of Funder/Sponsor: The funders had no role in study design, data collection, analysis, decision to publish, or manuscript preparation.

\section{Availability of data and materials}

Deidentified data are available for sharing. To request data, please contact the corresponding author with a request. Applications from investigators with the suitable academic capability to conduct the proposed work will be given consideration. Any proposal will require approval from the ethics committee which approved the conduct of this trial prior to sharing of any patient data. If a proposal is approved, a signed data transfer agreement will be required before data sharing.

\section{Code availability}

Not applicable.

\section{Declarations}

\section{Conflicts of interest}

None of the authors have any conflicts of interest to declare.

\section{Ethics approval}

All procedures performed in studies involving human participants were in accordance with the ethical standards of the institutional and/or national research committee and with the 1964 Helsinki Declaration and its later amendments or comparable ethical standards. The study was approved by the institutional review board of each participating hospital (IRB number B-1903-531-302 in Seoul National University Bundang Hospital, IRB Number 1903-063-1017 in Seoul National University Hospital, IRB Number H-1904-101001 in National Medical Center, and IRB Number 20-2019-23 in Seoul Boramae Hospital).

\section{Consent to participate}

Informed consent was obtained from all individual participants included in the study, and the consent of the deceased patient was waived.

\section{Consent for publication}

Not applicable.

\section{Open Access}

This article is licensed under a Creative Commons Attribution-NonCommercial 4.0 International License, which permits any non-commercial use, sharing, adaptation, distribution and reproduction in any medium or format, as long as you give appropriate credit to the original author(s) and the source, provide a link to the Creative Commons licence, and indicate if changes were made. The images or other third party material in this article are included in the article's Creative Commons licence, unless indicated otherwise in a credit line to the material. If material is not included in the article's Creative Commons licence and your intended use is not permitted by statutory regulation or exceeds the permitted use, you will need to obtain permission directly from the copyright holder. To view a copy of this licence, visit http://creativecommons.org/licen ses/by-nc/4.0/.

\section{Publisher's Note}

Springer Nature remains neutral with regard to jurisdictional claims in published maps and institutional affiliations.

Received: 25 August 2021 Accepted: 27 November 2021

Published online: 1 January 2022

\section{References}

1. Blinderman CD, Billings JA (2015) Comfort care for patients dying in the hospital. N Engl J Med 373:2549-2561. https://doi.org/10.1056/NEJMr a) 111746

2. Bernacki RE, Block SD (2014) Communication about serious illness care goals: a review and synthesis of best practices. JAMA Intern Med 174:1994-2003. https://doi.org/10.1001/jamainternmed.2014.5271

3. Truog RD, Campbell ML, Curtis JR, Haas CE, Luce JM, Rubenfeld GD, Rushton CH, Kaufman DC (2008) Recommendations for end-of-life care in the intensive care unit: a consensus statement by the American College [corrected] of Critical Care Medicine. Crit Care Med 36:953-963. https:// doi.org/10.1097/CCM.0B013E3181659096

4. In-young L (2007) [Viewpoint] Let terminally ill choose their death. Korea JoongAng Daily. https://koreajoongangdaily.joins.com/2007/06/13/ columns/ViewpointLet-terminally-ill-choose-their-death/2876725.html. Accessed 13 June 2006

5. National Agency for Management of Life-Sustaining Treatment [Internet]. Monthly statistics, Seoul: KoNIBP; 2019. Available from https://www.Ist.go. kr/eng/agen/konibp.do

6. Cho JY, Park JH, Kim J, Lee J, Park JS, Cho YJ, Yoon HI, Lee SM, Lee JH, Lee CT, Lee YJ (2019) Factors associated with quality of death in Korean ICUs as perceived by medical staff: a multicenter cross-sectional survey. Crit Care Med 47:1208-1215. https://doi.org/10.1097/CCM.0000000000 003853

7. Cho JY, Lee J, Lee SM, Park JH, Kim J, Kim Y, Lee SH, Park JS, Cho YJ, Yoon HI, Lee JH, Lee CT, Lee YJ (2018) Transcultural adaptation and validation of quality of dying and death questionnaire in medical intensive care units in South Korea. Acute Crit Care 33:95-101. https://doi.org/10.4266/acc. 2017.00612

8. The University of Washington School of Medicine End-of-Life Care Research Program: QODD Version 3.2: Healthcare Professional AfterDeath Self-Administered Questionnaire. University of Washington School of Medicine; Seattle, WA, USA. Accessed 02 February 2020. http://depts. washington.edu/eolcare/products/instruments

9. Bernal $J L$, Cummins S, Gasparrini A (2017) Interrupted time series regression for the evaluation of public health interventions: a tutorial. Int J Epidemiol 46(1):348-355. https://doi.org/10.1093/ije/dyw098

10. Pereira-Salgado A, Mader P, O'Callaghan C, Boyd L (2018) A website supporting sensitive religious and cultural advance care planning (ACPTalk): formative and summative evaluation. JMIR Res Protoc 7(4):e78. https:// doi.org/10.2196/resprot.8572

11. Mistry B, Bainbridge D, Bryant D, Tan Toyofuku S, Seow H (2015) What matters most for end-of-life care? Perspectives from community-based palliative care providers and administrators. BMJ Open 5(6):e007492. https://doi.org/10.1136/bmjopen-2014-007492

12. Bussmann S, Muders P, Zahrt-Omar CA, Escobar PL, Claus M, Schildmann J, Weber M (2015) Improving end-of-life care in hospitals: a qualitative analysis of bereaved families' experiences and suggestions. Am J Hosp Palliat Care 32(1):44-51. https://doi.org/10.1177/1049909113512718

13. Westbrook Jl, Woods A, Rob MI, Dunsmuir WT, Day RO (2010) Association of interruptions with an increased risk and severity of medication administration errors. Arch Intern Med 170:683-690. https://doi.org/10. 1001/archinternmed.2010.65

14. Noordermeer K, Rijpstra TA, Newhall D, Pelle AJ, van der Meer NJM (2013) Visiting policies in the adult intensive care units in the Netherlands: survey among ICU directors. ISRN Crit Care 2013:137045. https://doi.org/ $10.5402 / 2013 / 137045$ 
15. Netzer G, Iwashyna TJ (2017) Fair is fair: just visiting hours and reducing inequities. Ann Am Thorac Soc 14(12):1744-1746. https://doi.org/10. 1513/AnnalsATS.201706-4710l

16. Ministry and Health and Welfare (2019) The act on hospice and palliative care and decisions on life sustaining treatment for patients at the end of life, partial amendment. [Enforcement Date 28. Mar, 2019.] [Act No.15912, 11. Dec, 2018, Partial Amendment] https://elaw.klri.re.kr/eng_mobile/ viewer.do?hseq $=43945 \&$ type $=$ part\&key $=38$. Accessed date: 20 May 2021

17. Hodde NM, Engelberg RA, Treece PD, Steinberg KP, Curtis JR (2004) Factors associated with nurse assessment of the quality of dying and death in the intensive care unit. Crit Care Med 32:1648-1653. https://doi.org/10. 1097/01.ccm.0000133018.60866.5f

18. Levy CR, Ely EW, Payne K, Engelberg RA, Patrick DL, Curtis JR (2005) Quality of dying and death in two medical ICUs: perceptions of family and clinicians. Chest 127:1775-1783. https://doi.org/10.1378/chest.127.5.1775

19. Gerritsen RT, Hofhuis JGM, Koopmans M, van der Woude M, Bormans L, Hovingh A, Spronk PE (2013) Perception by family members and ICU staff of the quality of dying and death in the ICU: a prospective multicenter study in The Netherlands. Chest 143:357-363. https://doi.org/10.1378/ chest.12-0569

20. Gerritsen RT, Koopmans M, Hofhuis JG, Curtis JR, Jensen HI, Zijlstra JG, Engelberg RA, Spronk PE (2017) Comparing quality of dying and death perceived by family members and nurses for patients dying in US and
Dutch ICUs. Chest 151:298-307. https://doi.org/10.1016/j.chest.2016.09. 003

21. Kross EK, Engelberg RA, Downey L, Cuschieri J, Hallman MR, Longstreth WT, Tirschwell DL, Curtis JR (2014) Differences in end-of-life care in the ICU across patients cared for by medicine, surgery, neurology, and neurosurgery physicians. Chest 145:313-321. https://doi.org/10.1378/chest. 13-1351

22. Ko E, Lee J (2009) End-of-life communication: ethnic differences between Korean American and non-Hispanic White older adults. J Aging Health 21:967-984. https://doi.org/10.1177/0898264309344179

23. Kagawa-Singer M, Blackhall $L J$ (2001) Negotiating cross-cultural issues at the end of life: "You got to go where he lives." JAMA 286:2993-3001. https://doi.org/10.1001/jama.286.23.2993

24. Phua J, Joynt GM, Nishimura M, Deng Y, Myatra SN, Chan YH, Binh NG, Tan CC, Faruq MO, Arabi YM, Wahjuprajitno B, Liu SF, Hashemian SM, Kashif W, Staworn D, Palo JE, Koh Y (2016) Withholding and withdrawal of lifesustaining treatments in low-middle-income versus high-income Asian countries and regions. Intensive Care Med 42:1118-1127. https://doi.org/ 10.1007/s00134-016-4347-y

25. Park SY, Phua J, Nishimura M, Deng Y, Kang Y, Tada K, Koh Y (2018) Endof-life care in ICUs in East Asia: a comparison among China, Korea, and Japan. Crit Care Med 46:1114-1124. https://doi.org/10.1097/CCM.00000 00000003138 